\title{
De armarios virtuales a campos digitales de exterminio: interseccionalidad de Grindr fábrica de gaycidad chilena*
}

\section{From virtual cabinets to digital death camps: intersection of Grindr factory Chilean gayness}

\section{Luis Parra}

Universidad de Concepción, Concepción, Chile luis.parra.g27@gmail.com

\section{Resumen}

El presente trabajo es concebido como un estudio interseccional entre las distintas tecnologías de información, cuerpos, sexualidades, clase y raza. Su foco de análisis son las plataformas virtuales destinadas a hombres homosexuales, que componen un conjunto de páginas web y aplicaciones móviles (app), que median, gestionan y gobiernan el deseo de sus usuarios y el ejercicio de las sexualidades heterodisidentes. Tecnologías que configuran formas emergentes de sociabilidad en tiempo real y a cero metros de distancia, encontrando su expresión en un cruising virtual, que modela las subjetividades de sus usuarios. Se analiza centralmente a la aplicación Grindr que utiliza la geolocalizacion de sus usuarios. La interrogante que guía este trabajo de investigación, es cómo Grindr se convierte en un espacio interseccional que genera intimidad inmediata y/o cruising virtual, que vehiculiza formas de sociabilidad y prácticas sexuales, y en ultima instancia, configura y reconfigura la gaycidad en la actualidad, en Santiago de Chile.

Palabras claves: Interseccionalidad, Sexualidad y Tecnología, Grindr, mediación digital, cruising virtual

\section{Augusto Obando}

Universidad de la Frontera, Temuco, Chile augusto.obandoßagmail.com

\begin{abstract}
The present work is conceived as an intersectional study between the different technologies of information, bodies, sexualities, class and race. Its focus of analysis are the on line platforms intended for gay men, which make up a set of web pages and mobile applications (app), which mediate, manage and govern the desire of its users and the exercise of heterodisident sexualities. Technologies that set up emerging forms of sociability in real time and zero meters away, finding its expression in virtual cruising, which models the subjectivities of its users. The Grindr application that uses the geolocation of its users is centrally analized. The question guiding this research work is how Grindr becomes an intersectional space that generates immediate intimacy and/or virtual cruising, which conveys forms of sociability and sexual practices, and ultimately configures and reconfigures gayness today, in Santiago de Chile.
\end{abstract}

Key words: intersectionality, sexuality and technology, Grindr, digital mediation, online cruisingl

\footnotetext{
* El presente texto es parte de una investigación financiada por el FONDO DAE de Apoyo a la Investigación, de la Direc-
} ción de Asuntos estudiantiles de la Facultad de Ciencias Sociales, Universidad de Chile. 


\section{Introducción}

Partamos de la siguiente pregunta: ¿por qué estudiar Grindr? 0 más bien por qué convertir una aplicación móvil, como Grindr -que ha sido creada y diseñada para ser una app móvil, que facilita encuentros entre hombres homo-bisexuales- como un objeto de estudio interseccional que, a la vez, es un objeto inasible, virtual, individual y privado en su uso, y que, a su vez, es una de las aplicaciones de uso masificado en la comunidad gay y de los hombres que tienen sexo con hombres (HSH) a nivel global. Esta investigación parte de estos cuestionamientos, para poner en discusión los alcances y efectos de la mediación digital de la sexualidad, poniendo nuestro foco en el análisis de una base de datos de perfiles construida entre los años 2016 y 2019, además de una etnografía digital, que nos permitirá no solo caracterizar a los usuarios de Grindr, sino también comprender las complejas interacciones y usos que la aplicación posee.

El proceso de producción de un objeto de investigación puede darse a través de algo tan cotidiano, en la actualidad, como abrir una app móvil como Grindr y buscar alguna forma de intimidad inmediata, o bien por el mero ocio o curiosidad de saber, quién está cerca y disponible para entablar ya sea una conversación virtual, un encuentro o conversar, compartir un cigarrillo o cualquier otra forma de intimidad inmediata.

La teoría queer se sirve de distintos tipos de archivos y materiales, muchas veces proscritos o pertenecientes a la cultura popular. Por tanto, los objetos de investigación situados dentro de ella, son objetos en constante movimiento, interrelación y tensión. Son objetos mínimos, fronterizos y encarnados, siendo singulares y, además, glamorosos; pasan desapercibidos, porque son de uso masivo y de alto consumo, por tanto, de facto, pasan a ser invisibles/opacos, se naturalizan y se vuelven profundamente cotidianos, como el uso masificado de la internet y los smartphones, que gestionan deseos y aprenden de los hábitos y consumos de sus usuarios.

La app móvil es una plataforma virtual que vehiculiza y gobierna el deseo de sus usuarios a través de sus perfiles, expresados en cuadrillas, que se despliegan en forma de cascada, que hacen visible una multiplicidad de cuerpos fragmentados, deseantes de alguna practica sexual o, bien, recuadros vacíos y anónimos, que ofrecen algún tipo de servicio. En suma, este objeto de investigación que es Grindr y sus intersecciones se interroga por el qué hacen las locas ${ }^{1}$ y lo que no en una aplicación de celular, como Grindr y cómo a partir de esta plataforma se produce un cruising virtual, como forma emergente de sociabilidad a cero metros de distancia.

\section{Paradigma de la interseccionalidad: cuando los cuerpos son atropellados en las carreteras superpuestas de la dominación}

El concepto de interseccionalidad emerge del análisis del feminismo negro, en relación a la violencia de género y la triple dominación y opresión producida por el racismo, el sexismo y la clase. Para las mujeres de color (Crenshaw, 1991), la interseccionalidad permite entender violencias situadas y encarnadas en estas dimensiones.

Costa (2013) plantea que la noción de interseccionalidad permite comprender las formas de articulación política de los movimientos de clase, feministas y negros; donde dicha articulación fue formulada en primera instancia por Kimberlé Crenshaw (1991) y Hill Collins (2000), quienes criticaron al feminismo hegemónico de las sociedades occidentales modernas.

Se consideraba que la dimensión de género no lograba explicar plenamente la situación de opresión encarnada en las mujeres, ya que dejaba afuera los procesos de racialización, clasismo, la xenofobia, el racismo y la sexualidad, articuladas con el género para constituir situaciones particulares de invisibilización de la violencia, que muchas veces son simultáneas y opacas.

En los inicios de la conformación del paradigma de la Interseccionalidad, la intersección de las categorías centrales de clase, raza y género, se conceptualizaba utilizando como metáfora la intersección producida por varias carreteras (ver Figura 1), donde cada vía representa una de éstas tres categorías, pero se consideraba que cada una de ellas poseía el mismo valor y forma. 
La interseccionalidad ha sido un marco analítico que ha ganado popularidad, desde la cual han surgido nuevas perspectivas que la problematizan, critican y amplían, pero se continúa basando en el profundo compromiso teórico y jurisprudencial, que planteó la metáfora original de Crenshaw (Hancock, 2011, pp. 39)

Figura 1: Metáfora de la interseccionalidad según Crenshaw.

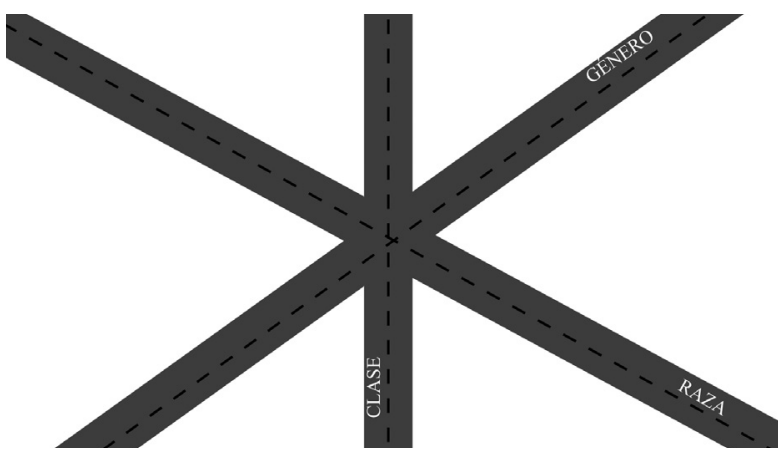

Fuente: Elaboración propia desde Hancock (2011).

Aun cuando la noción de interseccionalidad remite a la opresión, desigualdad y discriminación, según plantea Costa (2013) también los oprimidos en situaciones de exclusión pueden movilizarle para resistir estas condiciones y generar cambios colectivos.

El acercamiento a la interseccionalidad de Crenshaw puede ser entendido como sistémico, a diferencia de otros enfoques similares como los de Avtar Brah (1996), que posee un acercamiento más construccionista. En esta línea se plantea que:

Las teorías feministas de la interseccionalidad, focalizan el análisis develando las vías a través de las cuales el sistema sexo/género entra en interacción con otras categorizaciones socioculturales, y como la distribución diferenciada del poder y de la construcción identitaria, basadas en el género, la clase, la raza, la etnia, la posición geopolítica, la nacionalidad, sexualidad, discapacidad/capacidades, y edad, son interactuantes y mutuamente influyentes, unas a otras. (Likke 2010, p.208)
El feminismo marxista ha teorizado la relación entre género y clase; el feminismo postcolonial y anti racista, ha enfatizado la co-construcción del género, la raza, la etnia, la posición geopolítica y la nacionalidad; el feminismo queer se ha enfocado en la relación entre género, sexo, y sexualidad. Tal reflexión, interpela la transversalidad entre género, clase, raza, etnia, posición geopolítica, nacionalidad, sexualidad, discapacidad y edad. Éstas han sido integradas en la investigación feminista, tomando diferentes perspectivas, situándola bajo la conceptualización de interseccionalidad, adaptando del inglés americano de "cruces de caminos", “intersección”, que se vuelve a partir de 1990 (Likke, 2010). Este concepto se ha complejizado en la actualidad (ver Figura 2).

Figura 2: Metáforas de la interseccionalidad según actuales perspectivas.

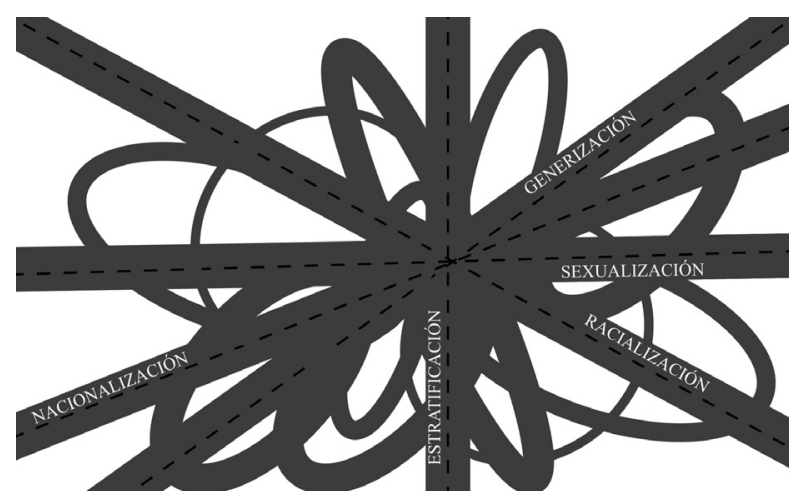

Fuente: Elaboración propia desde Hancock 2011.

Las dimensiones del paradigma de la interseccionalidad (ver Figura 3), proyectan la necesidad de analizar categorías múltiples, que poseen su diversidad interna, operando en un tiempo determinado y dinámico, configurando relaciones entre la individualidad e institucionalidad, apuntando a cuáles categorías se encuentran intersectadas (Hancock 2011, pp.51-52). Este paradigma plantea un acercamiento que va más allá de la identidad, con el propósito de crear y desarrollar coaliciones y agencia respecto a los múltiples planos o dimensiones de interacción de la dominación, con el fin de desmantelar y detener los complejos juegos olímpicos de la opresión y generar una política solidaria para el nuevo milenio, según Ange-Marie Hancock (2011). 
Figura 3: Dimensiones del Paradigma de la Interseccionalidad.

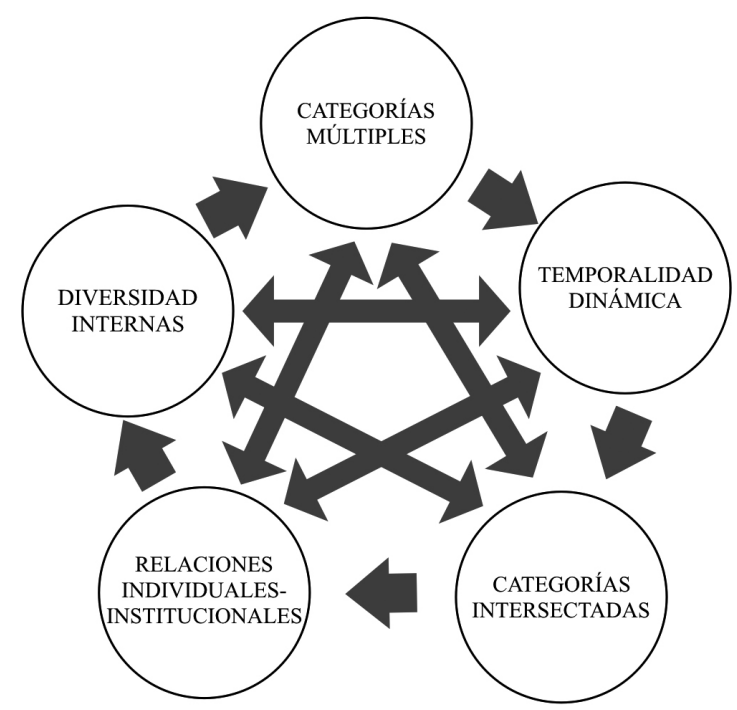

Fuente: Elaboración propia desde Hancock (2011).

\section{Desde el cuerpo sexuado y generizado a las encarnaciones virtuales}

Las categorías que se encuentran implicadas en el análisis interseccional del presente trabajo son altamente problemáticas, por lo cual es necesario hacer visibles los alcances del análisis procesual de estas, entendidas como procesos construccionistas, que operan contextualmente, y deben ser formuladas como sexualización, generización, racialización/etnización y estratificación económica. El advenimiento de los feminismos negros, los estudios poscoloniales y el feminismo decolonial han reformulado el concepto de raza y el proceso de racialización, ubicándose en un lugar protagónico en lo referente al estudio de la desigualdad (en lo particular) y de la investigación social (en lo generall, posibilitando con ello la inauguración de nuevas perspectivas analíticas para el actual paradigma de la interseccionalidad.

Esta yuxtaposición de perspectivas críticas, permite, por un lado, hacer frente a los procesos de exclusión y de violencia que generan el silencio de los cuerpos y voces racializados en occidente (Mignolo, 2009) y hacer frente al pensamiento del status quo, donde se naturaliza y se normaliza el sistema social de la opresión según la racializa- ción y generización de los cuerpos, es considerado como inexpugnable. Por último, plantea la posibilidad de pensar y vivir las fronteras, los bordes y los intersticios, para los cuerpos sexualizados, generizados y racializados por el heteropatriarcado, que son exiliados y sacrificados; donde la mestiza, chicana, lesbiana es una encarnación de este proceso (Anzaldúa, 1999).

Para Bastos (2016) la opresión sexual, de género y racial opera bajo en una lógica colonial, capitalista y heterosexista, dado que las formas de opresión se articulan en una forma interseccional. Con ello, los sujetos que son posicionados en la intersección de dichos cruces, sufren formas especificas de violencia y exclusión, que se superponen y operan simultáneamente vehiculizando discriminaciones múltiples.

\section{Metodología. Etnografías digitales y fenomenologías virtuales}

El presente trabajo caracteriza a los usuarios de la plataforma virtual Grindr a través de sus perfiles desde una perspectiva interseccional y adhiere al paradigma constructivista (Creswell \& Poth, 2018), desde un enfoque etnográfico y una perspectiva metodológica cualitativa (Faris, 2019). La estrategia de construcción/recolección de datos se basa en la observación participante de perfiles in situ en la aplicación que es coherente con la autoetnografía planteada por investigadorxs cuir (Faris, 2019). Dicha observación participante autoetnográfica se realizó interactuando, como usuarios en la aplicación, delimitando dos comunas encarnadas por un lugar de geolocalización específico, que son las respectivas estaciones de metro:

- Santiago Centro (Metro Universidad Católica)

- Puente Alto (Metro Plaza Puente Alto)

Se seleccionaron dichas comunas por su ubicación, para denotar la relación centro-periferia según la distribución de ingresos (Agostini, Hojman, Román, \& Valenzuela, 2016), asumiendo a priori, que ello responde a una relación basada en la clase, como posible eje interseccional de análisis. Dentro de la observación participante autoetnográfica se efectúa el registro fotográfico de perfiles en la aplicación en dos momentos: septiembre de 
2016 y marzo de 2019. Con ello, se tiene una visión diacrónica de lo que ocurre con la aplicación y las características de los perfiles entre estos dos años. Los smartphones tienen la posibilidad de registrar fotográficamente una imagen en la pantalla a través de una captura de pantalla, que es lo que se usó para los fines de registro de la presente investigación.

Ambos registros se realizaron en días laborales y a medio día, con ello se mantiene una visión sincrónica del fenómeno, ya que al ser capturados los perfiles en un momento del día específico se da nuevamente la posibilidad de rastrear cambios. La selección de los años se debe a que se posee una base de datos de perfiles de 2016 al 2019, construída en el marco de un proyecto investigativo mayor.

Para la observación participante se usó la versión de no pago de la aplicación Grindr. Durante el 2016, el registro de los perfiles se realizó de forma presencial en las estaciones de metro en la Región Metropolitana y durante el 2019 se realizó dicho registro a través de la herramienta de geolocalización propia de la aplicación, ubicándose georeferencialmente en cada estación de metro de la región.

Todos los perfiles observados en la aplicación a través de su función de cascada se transformaron en las unidades de análisis, generándose así una muestra-universo, ya que todos los perfiles fueron incluidos en el análisis.

Para el análisis se identificaron dos momentos:

- Primer momento: Se plantea una descripción de los perfiles según sus características, para luego analizarlos desde una perspectiva interseccional. La caracterización se realiza a través de una observación y análisis de los componentes visuales y textuales presentes en la cascada de los perfiles ( 30 perfiles analizados aproximadamente) (ver Figura 4), se generan categorías de forma inductiva, las cuales fueron agrupadas en un gráfico de jerarquías para denotar cómo se distribuyen las principales características que poseen los perfiles según su geolocalización.
Las categorías más frecuentes observadas son:

a) Conexión: (conectado o no conectado) Se debe colocar de manifiesto, que aun cuando se identifique el perfil como "no conectado", este estuvo hace menos de una hora en la aplicación, ya que es el tiempo que posee el algoritmo de la aplicación para sacarlo de la cascada de perfiles. Y, por otra parte, aun cuando no se esté conectado, se envían desde la app notificaciones a los usuarios para que estos revisen el mensaje enviado a su perfil. Es por ello que al parecer en Grindr opera un tiempo ubicuo y total, sin pausa.

b) Cruising virtual: Esta categoría se basa en la lectura de la zona del perfil descrita por la app como "mi nombre" y "sobre mi", que va desde el "conociendo", hasta "sexo ahora", entendidas como declaraciones explicitas de interacciones de tipo sexual.

c) Cuerpo completo con desnudo parcial: La aplicación posee normas comunitarias estrictas acerca de imagen de perfil, no permite el desnudo frontal o explicito, dejando aquello para las imágenes que los usuarios se envían de forma privada a través de los mensajes en la aplicación.

d) Cuerpo musculado: Esta categoría emerge de la observación y revisión de las imágenes de perfil que denotan un cuerpo tonificado y con trabajo de gimnasio.

e) Rol sexual: la aplicación posee para la clasificación del perfil categorías especificas relacionadas con el rol sexual. Sin embargo, los usuarios en la zona del perfil descrita por la app como "mi nombre" y "sobre mi", exhiben su rol con frases tales como "Pas", "top", o emojis como el durazno o la berenjena que, a su vez, representan atributos físicos de "buen trasero" y sobre el tamaño del pene; o signos/ símbolos que representan el rol, flechas hacia arriba (activo) abajo (pasivo) circulares (inter/versátill.

f) Rostro; gl Torso desnudo; h) imagen cualquiera; i) Nombre o apodo; jl perfil vacío. 
Figura 4: Cascada tipo de perfiles de Grindr ${ }^{2}$

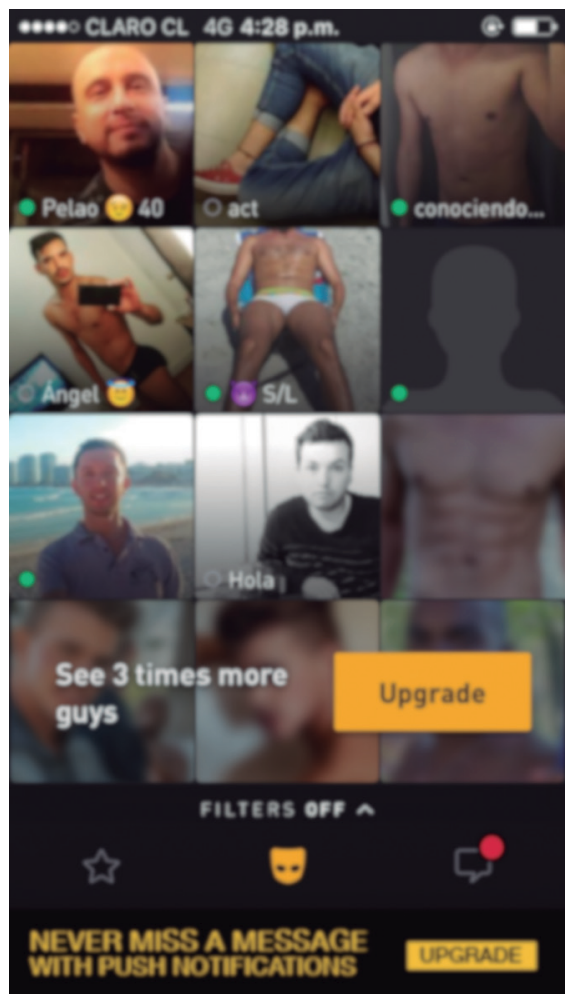

Fuente: Captura de App de Grindr.

- Segundo momento: a partir de los datos de perfiles, se realizó un muestreo por conveniencia, para seleccionar "perfiles tipo" que den cuenta de las principales características de los usuarios de la aplicación. Posteriormente, se esbozó un análisis interseccional desde la información visual y escrita que poseen dichos perfiles tipos. Se seleccionaron 8 perfiles que se destacaban debido a su identidad sexual (homosexuales, bisexuales, heterosexuales), a su identidad de género (hombre cis, mujer trans) ${ }^{3}$, a la información visual y escrita que contenían, para dar cuenta de los fenómenos y procesos de dominación, exclusión y violencia, operantes de forma interseccional dentro de la aplicación.

Un aspecto relevante en esta investigación es lo referente a los aspectos éticos. Al no ser posible la obtención de un consentimiento informado a los usuarios de perfiles, se decidió resguardar el anonimato de los sujetos eliminando las imágenes del perfil, y hacer imposible su identificación, solo manteniendo cierta información relevante de ellos.

\section{Análisis de perfiles de usuarixs de Grindr: de la materialidad del cuerpo a la ciberencarnación}

Se observa entre los años 2016 y 2019 una transformación de las características presentes en los perfiles en la comuna de Puente Alto, donde el rostro en el perfil pasa a ser desplazado por el perfil vacío o por cualquier imagen en éste. Se infiere, que dicho fenómeno se debe a la homofobia que opera como marca de clase. Por lo tanto, en sectores donde hay menores ingresos, tienden a aparecer perfiles sin imagen y sin información para mantener el anonimato $y$, con ello, mantener la privacidad en un espacio virtual que ya es privado dentro de la app.

Gráfico 1: perfiles metro Plaza Puente Alto 2016

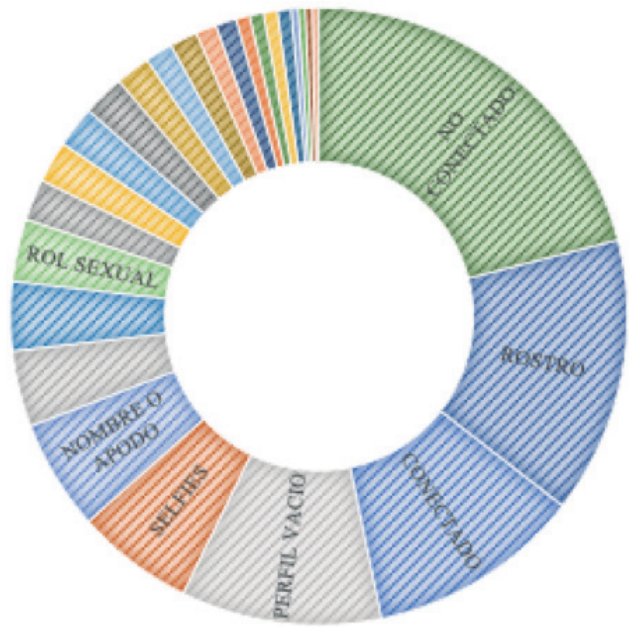

Fuente: Elaboración propia

Gráfico 2: perfiles metro Plaza de Puente Alto 2019

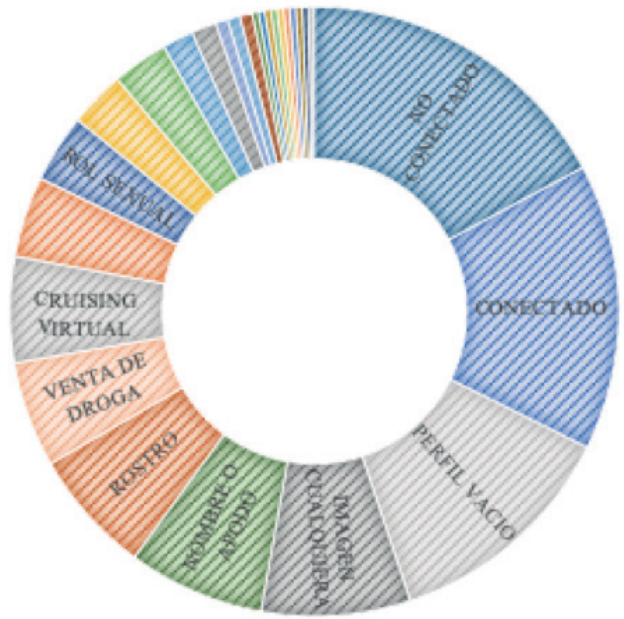

Fuente: Elaboración propia 
Para explicar el hallazgo del aumento de perfiles vacíos, puede proponerse una posible homofobia introyectada, siguiendo a Eve Kosofky Sedgwick en la Epistemología del armario (1998), donde los sujetos homosexuales tratan de hacerse pasar por heterosexuales creando una performance coherente para la sociedad heteronormada. Sin embargo, esta siempre falla, generando angustia ante la exposición y descubrimiento de la propia homosexualidad. Es posible reflexionar sobre los "armarios digitales" que crea la aplicación, por un lado, como espacio de mantención del deseo en forma de anonimato total y, por otro, como protección de los sujetxs de la disidencia sexual, en los casos de contextos de violencia homo/transfóbica material contra ellxs. Solo que dicho armario digital tiene su límite, en el momento de la materialización de la interacción, ya que es necesario salir fuera de Grindr para encontrarse con otro, solo que esta salida del armario digital no opera como el Outing (Spargo, 2004), ya que no se platea aquí la necesidad de asumir ninguna identificación identitaria, incluso es posible continuar con el anonimato.

Esta característica de doble pliegue de lo privado es llamativa de la aplicación, ya que permite la identidad fluida y el anonimato total (Gomez, 2018). Sin embargo, dicho anonimato también plantea un riesgo para la integridad y seguridad de los usuarios (Beas Anduaga-Beramendi, Maticorena-Quevedo, Vizcarra-Melgar, \& Mariño, 2016)

Es también relevante cómo se posiciona el cruising virtual como categoría: se observa, de hecho, en las economías afectivas y sexuales que propone la aplicación, forjadas por la intersección de los procesos de sexualización, generación, racialización y estratificación de los cuerpos (Raj, 2011). La aparición reciente de la venta de drogas en el uso de la $a p p$, en el contexto territorializado de la comuna, puede entenderse bajo la lógica del doble pliegue de lo privado. Con ello, Grindr se transforma en un espacio Otro, no solo para el cruising virtual, sino para situaciones al borde de la ley.

En 2016, en la comuna de Santiago Centro, en la geolocalización del Metro Universidad Católica, se observan las categorías de rostro en el perfil, el cuerpo musculado, el cruising virtual y la declaración del rol sexual. Ello se acentúa y acrecienta en el 2019: el cuerpo musculado y el cruising virtual toman preponderancia como categorías, su-
Grafico 3: perfiles metro Universidad Católica 2016

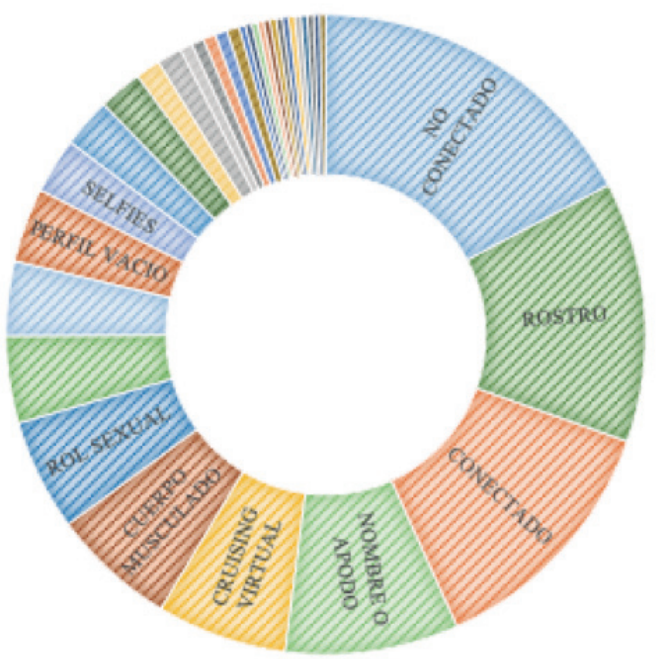

Fuente: Elaboración propia

Grafico 4: perfiles metro Universidad Católica 2019

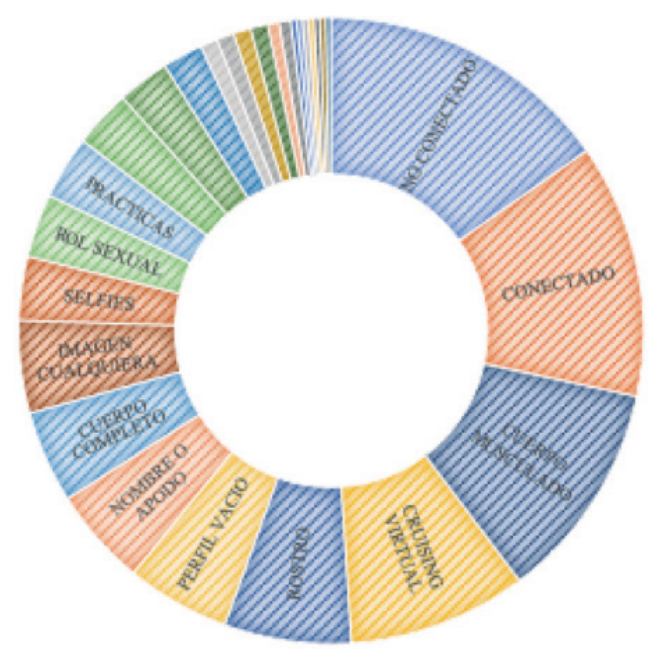

Fuente: Elaboración propia

perando en jerarquía al rostro. Lo anterior puede explicarse, posiblemente, debido a que este sector de Santiago Centro (junto con Bellas Artes y la comuna de Providencia), poseen una identidad territorial para los sujetos homosexuales en la ciudad de Santiago (Cortés, 2016). A ello se suma una concentración masiva de perfiles en la app, lo que generaría la sensación de mayor protección ante la homofobia que opera en términos de clase y desigualdad territorial. Además, se esboza una posible configuración de idea de sociabilidad que produce una "comunidad gay", lo que es un elemento protector para los sujetos, sea esto real o no. 
Sin embargo, tal comunidad, bajo las lógicas de cruising virtual y de la inmediatez, opera más bien como un "vecindario virtual sexual" -y no una comunidad-, ya que no se participa de la sociabilidad en el espacio público, sino que hay una virtualización anónima de la sociabilidad con fines de sexo inmediato (Roth, 2016; Mowlabocus, 2016; Miskolci, 2015). Por otra parte, que emerja en las imágenes de los perfiles el cuerpo musculado, denota también una cierta superposición de procesos asociados a marcas de clase, sexualización y generización de los cuerpos, ya que estos responden a una estética hipermasculina, donde se valora y se preconiza la musculación, la inversión en horas de gimnasio, suplementos de esteroides, etcétera. Se configura así, un circuito de producción no solo de un cuerpo, sino de un cuerpo para -en aras de una subjetividad gay permeada por el mercado- la industria pornográfica que levanta un tipo de cuerpo deseable específico que moldea el deseo gay y transforma la identidad gay en gaycidad, que consiste en la conjunción y sedimentación de estos aspectos. (Roth, 2016; Reyes Gil, 2018; Mowlabocus, 2010).

A continuación, se presentan los 8 perfiles-tipo, seleccionados desde la base de datos para realizar el análisis interseccional y dar cuenta de las relaciones de dominaciones y poder en la aplicación.

Figura 5. Perfil Usuario.

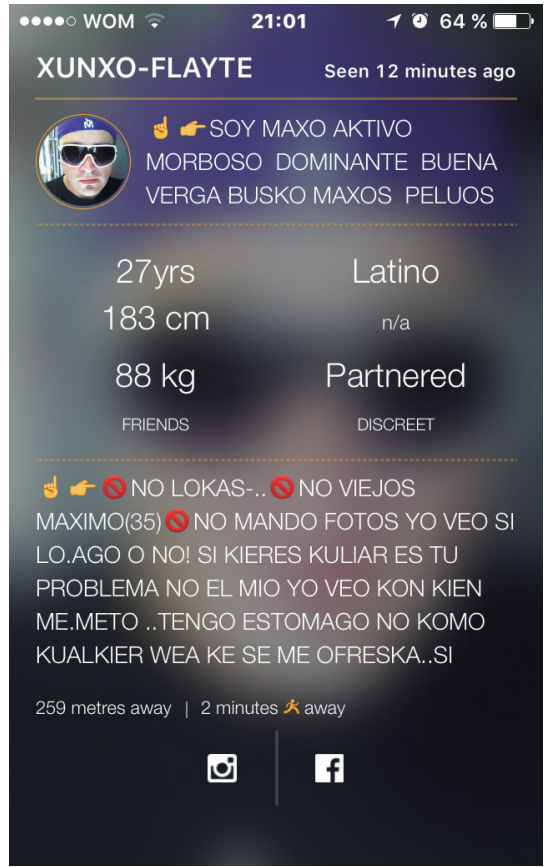

Fuente: Bases de datos de perfiles 2016 a 2019
El sujeto se autodenomina "Xunxo-Flayte", lo cual le ubica en una identidad de clase particular. "Soy macho activo morboso dominante buena verga busco maxos peluos". Con esta descripción de sí mismo se sitúa en la masculinidad hegemónica imbricada a la homosexualidad, ya que refuerza su rol sexual activo, sus prácticas sexuales, las características de su pene y la búsqueda de sujetos similares a él.

“no lokas, no viejos, máximo 35, no mando foto, yo veo si lo ago o no!, si kieres kuliar es tu problema..tengo estomago, no komo kualkier wea ke se me ofreska. si"

Al plantear que no gusta de "lokas" denota la exclusión de la femenino/afeminado, como una forma de interrelación entre homosexualidad y masculinidad hegemónica, donde se preconiza lo masculino como norma. También expresa una discriminación por edad. Por tanto, los sujetos de cierta edad son deseables y otros excluidos (35 años). Declara, por último, que la fotografía es un medio de prueba acerca de la corporalidad del otro, como sujeto deseable y con ello plantea que sus estándares excluirán a todo aquello, que él considere "kualquier wea" ${ }^{\prime \prime}$

Figura 6. Perfil Usuario.

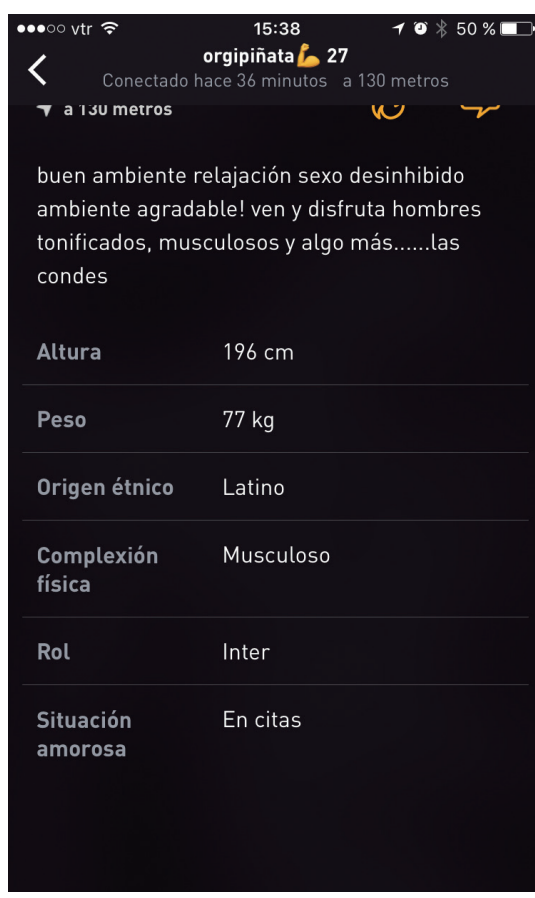

Fuente: Bases de datos de perfiles 2016 a 2019 
Este perfil no pertenece a un sujeto individual sino a uno grupal/colectivo "Orgipiñata".

“buen ambiente, relajación, sexo desinhibido, ambiente agradable!, ven y disfruta hombres tonificados, musculosos y algo mas ... Las Condes".

El sujeto ofrece un cruising virtual y material, pero que puede interpretarse incluso como comercio sexual. Se destaca que los cuerpos son masculinos, tonificados y musculosos. Con ello, claramente, delimita un estándar corporal para quien quiera participar de una orgía. Por último, da cuenta de la clase social a la cual pertenece al denotar su localización en un sector de altos ingresos de Santiago (Las Condes).

“Altura: $196 \mathrm{~cm}$, peso: 77 kg, origen étnico: latino, complexión física: musculoso, rol: Inter, situación amorosa: en citas". Grindr permite la elección de características para describirse y este perfil posee una corporalidad asociada a ciertos cánones de belleza del cuerpo fitness, además de develar su rol sexual y su situación sentimental, siendo la aplicación quien entrega tales parámetros de forma prestablecida.

Figura 7. Perfil Usuario.

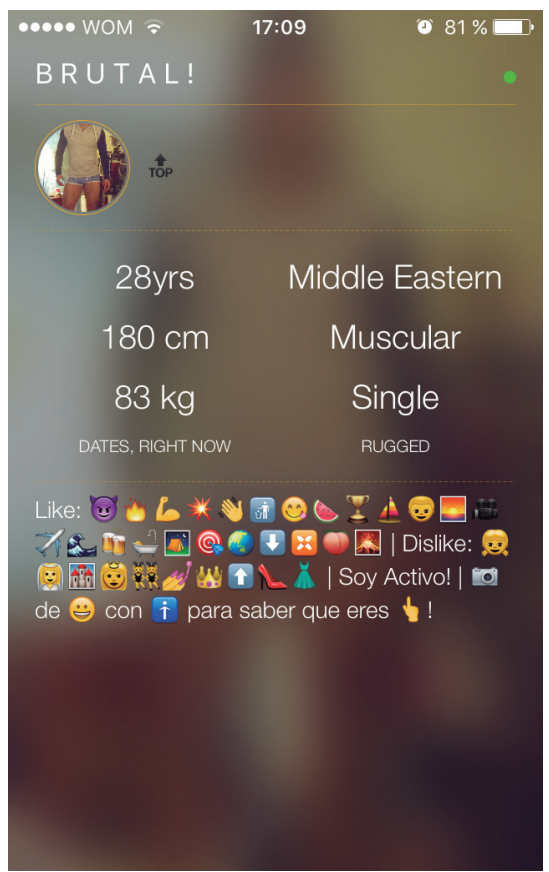

Fuente: Bases de datos de perfiles 2016 a 2019
La imagen del perfil de la Figura 7 muestra a un hombre joven y tonificado de pie, en ropa interior, en una habitación con cierto grado de desorden, lo que puede ser su dormitorio. Aun cuando el torso esté cubierto, se percibe un cuerpo tonificado lasí lo exhiben las piernas de la fotografía de su perfill. La postura y la forma de estar vestido/desvestido también se entiende como una erotización de este cuerpo, para hacerlo deseable. Por ello, el cuerpo masculino deviene en este caso en un cuerpo deseable, un cuerpo sexualizado, y un cuerpo trabajado para el cruising sexual, terminando con ello en la transacción de cuerpo por placer.

El sujeto "brutal" es "[?]" lo que se interpreta desde el lenguaje de los emojis como "activo", siendo este su rol sexual. A través de la lectura de los emojis, se pueden observar e interpretar algunas de sus preferencias en el ámbito sexual: gusta del morbo, el sexo caliente, los músculos, el spanking (golpear las nalgas de su pareja sexuall y la higiene. Los sujetos pasivos con buen trasero y que sean calientes, además del sexo grupal, solo que ese emoji no se encuentra actualmente disponible, en el cual varias flechas convergen en un punto.

De la lectura de los emojis de la Figura 7, se interpreta claramente que no le gustan sujetos afeminados, niñas, reinas, princesas y todo tipo de sujeto feminizado, excluyéndolos de su búsqueda. Puntualiza que su rol sexual es activo, articulando como en otros perfiles, el discurso de la homosexualidad junto al de la masculinidad hegemónica. Él es activo y, con esto, nuevamente articula un rol sexual, una identidad sexual y genérica. Por último, necesita una foto de rostro y cuerpo para saber quién es su interlocutor y, con ello, evaluar estéticamente a quién será su pareja sexual.

En la figura 8 se observa a una mujer joven, en una pose sugestiva, con un vestido de color rosado ceñido. No es obvio percatarse de que el sujeto es trans o que ha cursado una transición desde la masculinidad. "\$Nicole" es de los pocos cuerpos trans que logran encontrarse en la aplicación, los signos “\$” denotan que la persona ejerce el comercio sexual. "[E]scorts travsty lobita recién llegada a santiago". Esta descripción da cuenta de la posición del sujeto trans, como sujeto generizado, sexualizado y, en este caso, posiblemente pauperizado: se describe su reciente llegada a Santiago, lo que implica que eventualmente proviene de otras 
Figura 8. Perfil de Usuario.

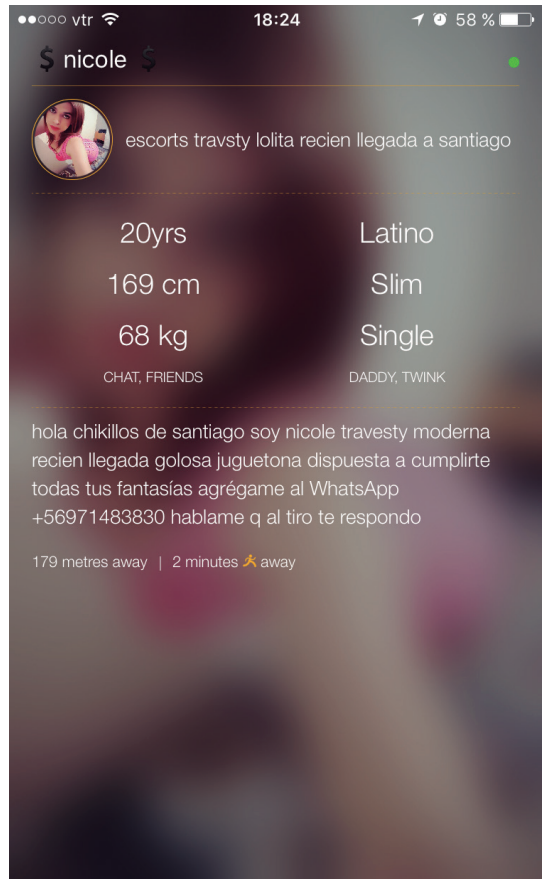

Fuente: Bases de datos de perfiles 2016 a 2019

regiones del país o puede ser migrante. Se describe como un sujeto trans (travesti) declara su rol sexual (moderna) y que ejerce el comercio sexual. Se deja entrever que es chilena debido al uso del vocablo "altiro", que no es usado por personas migrante en su sentido "inmediato".

Figura 9. Perfil de Usuario

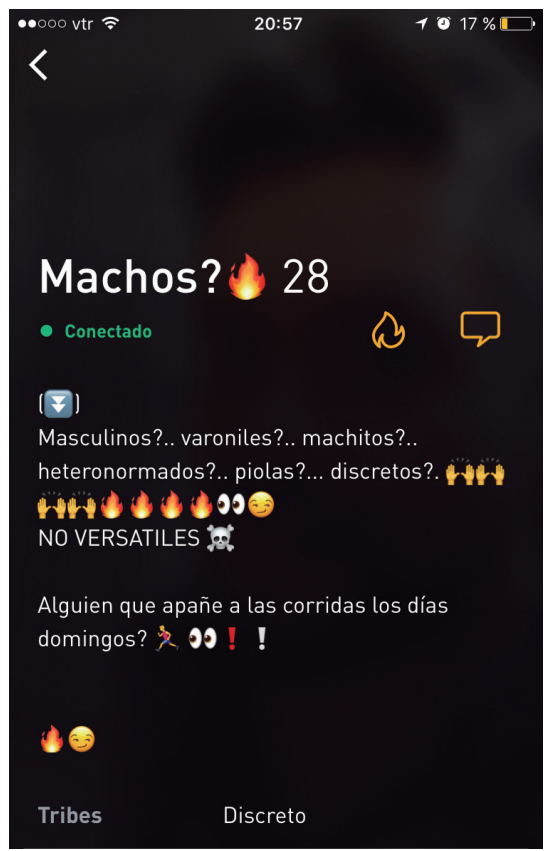

Fuente: Bases de datos de perfiles 2016 a 2019
El sujeto "machos?" de la figura 9 usa el emoji "[?]"5 y con ello describe su rol sexual, que es pasivo: "masculinos?varoniles?machitos?heteronorm ados?piolas?discretos? no versátiles. Alguien que apañe a las corridas los días domingos?". Lo anterior describe algo muy recurrente en los perfiles en Grindr: la búsqueda de sujetos que se construyan en torno a la masculinidad hegemónica. Es esta cita a la heteronorma la que parece atraer a los usuarios de la app. No es la heterosexualidad en sí, sino aquello que es producido en la intersección de la heterosexualidad y la masculinidad, lo que es una identidad, que se ubica en el supuesto vértice de la jerarquía y en ápice de los privilegios.

En relación a lo de "es nuevamente la desvalorización de lo femenino y del afeminamiento en los sujetos, exigiendo que sea imperceptible su orientación sexual, para que nadie se dé cuenta. Se autodenomina como "discreto", por lo tanto, podemos asumir que tal sujeto no logra, ni puede asumir su orientación sexual en el contexto material, donde vive, con ello cursa una homofobia tal, que ya es introyectada y proyectada inclusive en este espacio virtual

Figura 10. Perfil de usuario.

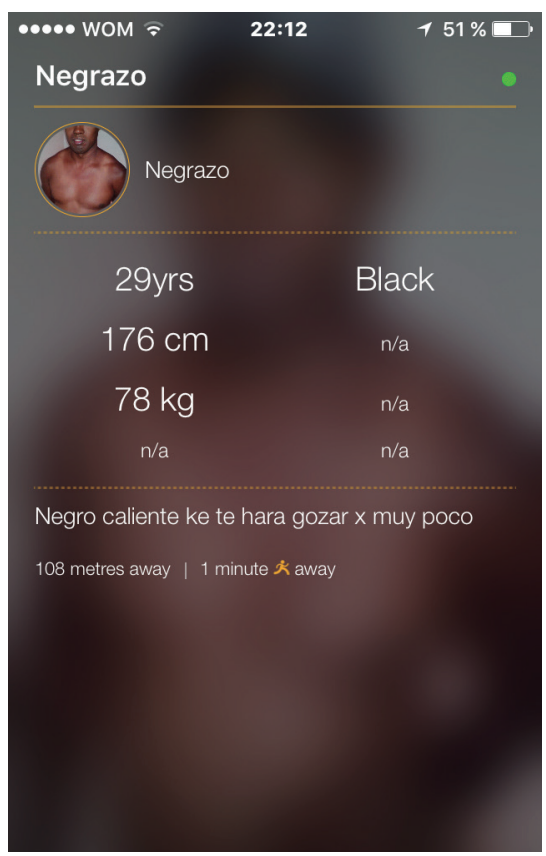

Fuente: Bases de datos de perfiles 2016 a 2019 
El sujeto "Negrazo" es un cuerpo racializado. Se describe como: "negro caliente ke te hara gozar $x$ muy poco", "29 años de edad, 176 cm, 78 kg, negro". Se infiere a través de la descripción en el perfil, que ejerce el comercio sexual. Junto a la racialización de su cuerpo, hay una erotización para sexualizarlo como objeto/sujeto de deseo. Los procesos migratorios actuales en Chile, concentran en Santiago, como capital, a un mayor contingente de personas migrantes, las cuales se han enfrentado a los fenómenos de racismo y xenofobia que son más agudos hacia personas negras, posicionadas en lugares de precarización y exclusión del mundo laboral y donde el comercio sexual es una estrategia de sobrevivencia.

Es también necesario puntualizar que el comercio sexual ejercido por hombres, difiere al de las mujeres, ya que estos enfrentan en menor medida la trata y explotación sexual. Por otra parte, los sujetos que la ejercen son, en su mayoría, heterosexuales. Debido al uso de esta estrategia de sobrevivencia, tienen prácticas sexuales con otros hombres, generando una reconfiguración en el espacio de la identidad sexual, que muchas veces no es tensionada, pero sí flexibilizada, ante lo cual emergen categorías de nominación, como los hombres que tienen sexo con hombres (HSH).

Figura 11: Perfil de Usuario.

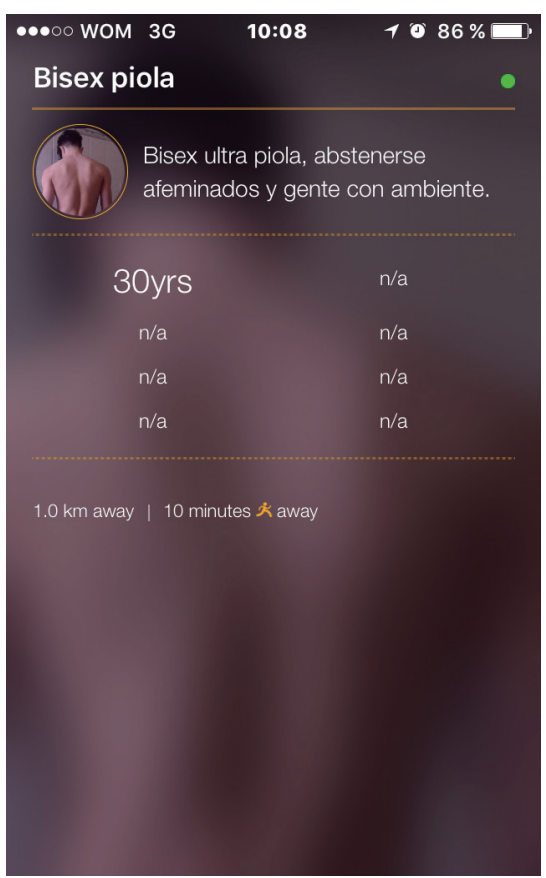

Fuente: Bases de datos de perfiles 2016 a 2019
El sujeto “Bisex piola”, devela así su identidad sexual, no heterosexual u homosexual, lo cual dado el contexto de dicotomía hetero/homo, es invisibilizada. Por otra parte, "piola" remite a la necesidad de anonimato, posiblemente debido a la bifobia, tanto desde la heterosexualidad como desde la homosexualidad, por la incomprensión del deseo bisexual.

Se describe como: “bisex, ultrapiola, abstenerse afeminado y gente con ambiente", lo que describe nuevamente su posicionamiento en la masculinidad hegemónica, donde el ser “ultra piola” está basado en el anonimato y en la no pertenencia a la homosexualidad. "Gente sin ambiente" son articulaciones de este mandato heteronormado. Por último, vuelve a articularse identidad sexual y masculinidad hegemónica, con el fin de excluir lo femenino/afeminado, en este caso, como formas proscritas del deseo homosexual.

Figura 12: Perfil de Usuario.

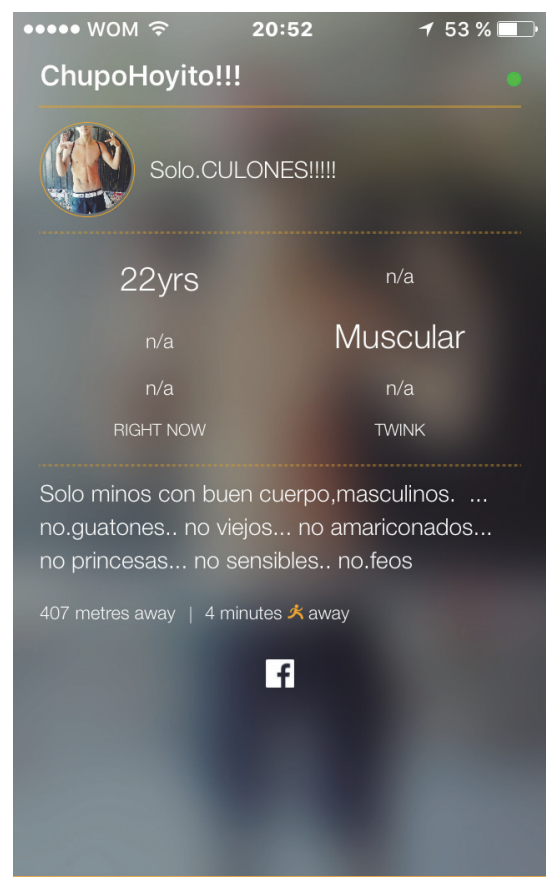

Fuente: Bases de datos de perfiles 2016 a 2019

El sujeto "ChupoHoyito!!!" se posiciona desde sus practicas sexuales denotando su rol sexual. En tanto sujeto homosexual, declara una lista de sujetos deseables y excluibles:

solo culones”, “22 años, muscular, buscando para ahora mismo, tribu: Twink" "solo minos con buen 
cuerpo, masculinos, no guatones, no viejos, no amariconados, no princesas, no sensibles, no feos.

Lo anterior, devela nuevamente el entrecruce de la identidad sexual y el género. Con ello, homosexualidad y sus prácticas sexuales no heteronormadas se articulan sin problemas con la masculinidad hegemónica, como eje productor de subjetividad. Para este sujeto en lo singular, como para varios de los usuarios de Grindr, el deseo opera en torno al cuerpo tonificado o musculado, junto a una performance masculina. En contraposición opera la "gordofobia" (Navajas-Pertegás, 2017; Suárez García, 2017), discriminación por edad, misoginia y homofobia, la devaluación de lo femenino, unido a la "feo-fobia", generando jerarquización, exclusión y violencia dentro de la aplicación.

Este es un complejo escenario, donde el contexto material de los usuarios de la aplicación es altamente violento. Dada esta superposición interseccional de la dominación, podría esperarse que en Grindr existiría una heterotopia (Foucault, 2010), donde se suspenden los procesos de exclusión, dominación y violencia que operan en lo social. Sin embargo, este "armario virtual" de protección, no sería más que un campo de exterminio simbólico virtual, en que la violencia es digital.

\section{Conclusiones: Los juegos olímpicos de la dominación en las plataformas virtuales del deseo}

La figura 13 presenta la interrelación de los perfiles previamente descritos, empleando una lógica interseccional, donde el eje de la clase y sus procesos de estratificación atraviesan todos los perfiles. La generización es fundada por la masculinidad hegemónica, la sexualización es dada por la identidad sexual que los sujetos declaran en los perfiles con sus roles sexuales asociados a estas identidades, mientras que la racialización y feminización son procesos periféricos de articulación.

La interseccionalidad en Grindr se plantea como una superposición y cruce de variables como sexo, género, raza/etnia, clase, edad, tipo de cuerpo, pertenencia a tribus y rol sexual, solo por nombrar algunas. Estos cruces generan capital corporal (Bourdieu, 1990, p.137) y capital erótico (Hakim 2012). Este concepto que va mas allá del atractivo sexual, intersectando cuerpo, sexualidad, atractivo, encanto y vitalidad.

Esta interseccionalidad produce un tipo ideal de perfil como cita fallida a la masculinidad hegemónica heterosexual y blanca. Este perfil altamente

\section{Figura 13. Interseccionalidad en Grindr ${ }^{6}$}

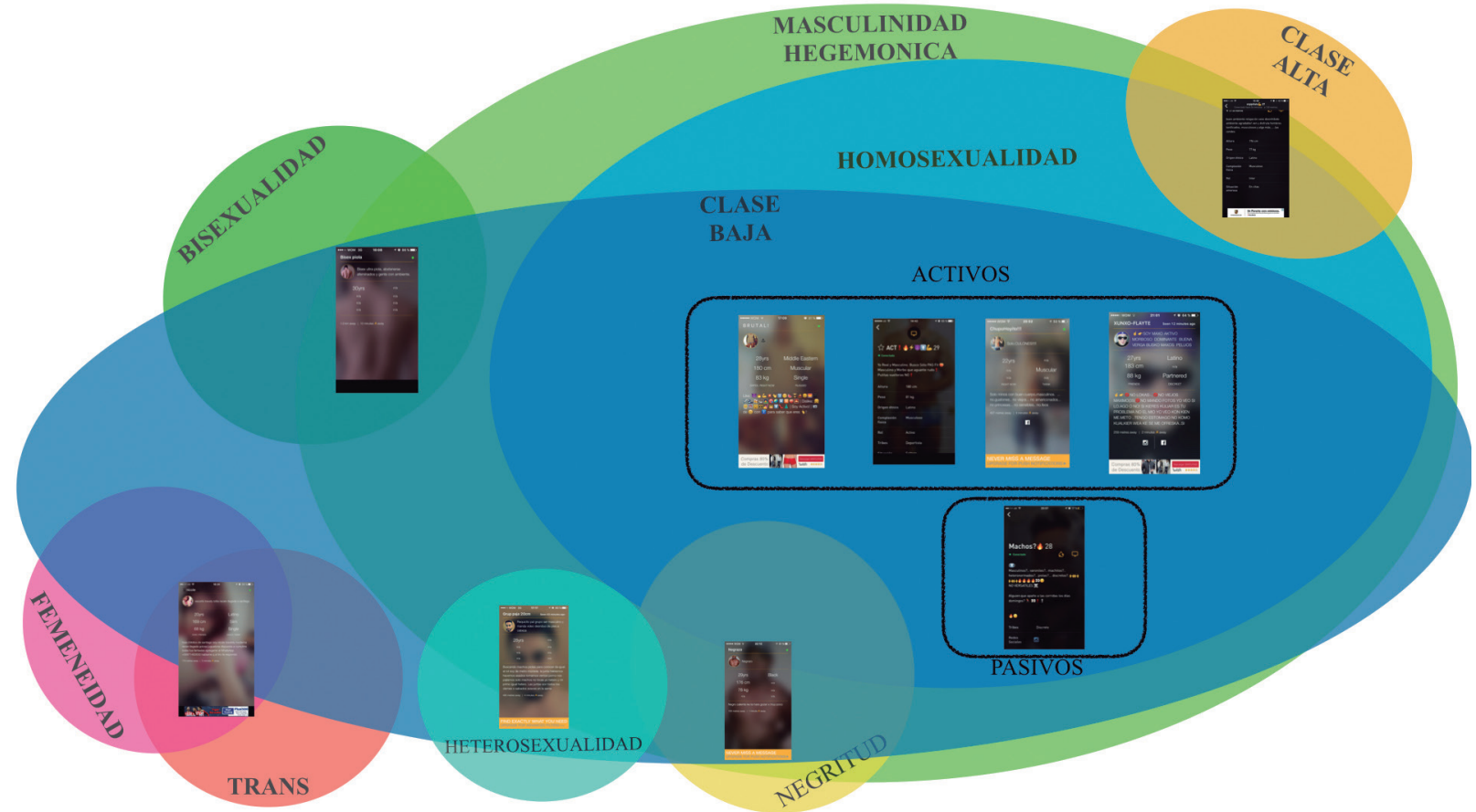

Fuente: Elaboración Propia 
atractivo se posiciona como ideal homo/normativo, localizado en los sectores de mayor nivel socioeconómico de Santiago. El cuerpo musculado es la norma de la gaycidad globalizada, eje central de la masculinidad gay que obtiene sus códigos de erotización y comercialización de la industria pornográfica gay (Roth, 2016; Mowlabocus, 2010).

En contraparte, existen perfiles rechazables caracterizados por la intersección de categorías consideradas negativas o discriminables en el interior de esta aplicación, debido a su jerarquizado posicionamiento y valoración de características. Lo femenino actúa como un diferencial de exclusión, manifestándose en la ausencia de cuerpos generizados de mujeres en la aplicación. Incluso lo considerado afeminado es rechazado (Gómez Beltrán, 2018).

La clase o estratificación económica actúa como diferencial en los perfiles cuando presentan características estéticas como: la calidad de la imagen, su estética, rasgos físicos blancos, junto a cuerpos musculados, su ropa y teléfono móvil. Cuando el perfil está geolocalizado en un lugar de alto nivel de ingreso, aumenta la frecuencia de perfiles de cuerpos hipermasculinos, musculados, erotizados y pornográficos. Donde el acceso a gimnasio, dieta y uso de anabólicos son tecnologías de producción corporal mediadas por la clase. Aun cuando fue posible encontrar esas mismas características estéticas en perfiles geolocalizados en sectores de bajos ingresos, son infrecuentes y responden a la lógica de homogenización planteada por la hegemonía de la homonormatividad.

Lo trans y vivir con VIH lambas características consideradas tribus en la appl son perfiles casi inexistentes en la aplicación. Con ello volvemos a la idea de valoración y discriminación que opera interseccionalmente en la aplicación, pudiéndose plantear que los fenómenos de transfobia y serofobia presentes en la sociedad aparecen en la aplicación. Adherir o usar dichas categorías ubica al perfil y a quien lo usa en un lugar de rechazo y discriminación.

El perfil vacío puede leerse a través de su posicionamiento geopolítico, ya que es altamente frecuente en sectores de menor ingreso tanto en Santiago como en regiones, poniendo de manifiesto la relación centro-periferia a nivel del país, lo que se interpreta como producto de la homofobia que opera en variados contextos sociales y culturales de Chile. No mostrarse o no ser visible constituye una forma de proteger la integridad física, pero además plantea la paradoja presente en la epistemología del armario. Esta aplicación es un doble pliegue de lo privado en lo público, porque existe en el pliegue privado del celular que es privado y personal. La heteronormatividad hace creer a quienes usan Grindr que se les cree sus performances de hacerse pasar por heterosexuales (Sedgwick, 1998).

Entenderemos por tanto capital corporal y capital erótico (Bourdieu, 1990; Hakim, 2012) como aquel capital que se basa en el valor del cuerpo, construyéndose mediante la inversión, intervención y acciones que se realizan sobre la corporalidad, para aumentar su valor con fines de optimización. Su propósito es cumplir con los estándares estéticos imperantes, lo que generará posteriores intercambios y convertirá al cuerpo en bien de consumo. Grindr es un lugar de emergencia e intercambio de capital corporal y capital erótico que ingresa en las lógicas de desecho de la gaycidad neoliberalizada (Gómez Beltrán, 2018; Gómez, 2018).

Lo complejo del análisis reside en desenmarañar la superposición de las categorías de opresión y cómo generan procesos de violencia y exclusión. Este trabajo explora cómo una app móvil, se convierte en un espacio hegemónico de construcción de la gaycidad, que genera exclusiones superpuestas, desde la sexualización/generización y que produce la gaycidad/masculinidad, como homonormatividad territorializada (Brown, 2012) y homonacionalismo (Andrade, 2014) articulados con el capitalismo en clave neoliberal del contexto chileno (Salazar, 2011).

Cabe preguntarse si es posible entender a Grin$d r$ como producción de deseo y tecnología de gobierno y gestión (Deleuze \& Guattari, 1985). Esta aplicación tecnológica se comporta como una tecnología de gobierno y producción de deseo, en la medida que todo cuerpo desea ser fabricado en la lógica del consumo, cuyo final es el desecho. Existen sujetos desechados a priori, y otros que lo son en el proceso. Sin embargo, en todos los cuerpos opera el gobierno del deseo.

Lemebel afirmaba que ser pobre y ser maricón es peor (Lemebel, 2009). Sin embargo, entre las in- 
terseccionalidades construidas por Grindr, existen varias que superan con creces la anterior o que la amplían y profundizan. Estas afectan las vidas materiales de los usuarios de la aplicación por lo que se concluye que este armario virtual solo deviene en un campo de exterminio digital.

\section{Notas}

1 Localismo chileno para referirse a sujetos homosexuales afeminados.

2 Se difuminaron las imágenes para protección de identidad.
3 Cabe destacar que mujeres cis no se encontraron en la base de datos y menos hombres trans, por lo cual no fue posible incluirles en el análisis.

4 Este localismo chileno se traduce como "cualquier cosa", "lo que sea".

5 Los usuarios de la app, usan estos emoji flecha arriba y abajo, para indicar su rol sexual. Arriba=activo, Abajo=pasivo, flechas en ambas direcciones indican versatilidad en el rol.

6 Se eliminaron imágenes con los rostros para proteger la identidad.

\section{Referencias}

Andrade, B. (2014). Homonacionalismo e cidadania LGBT em tempos de neoliberalismo: dilemas e impasses às lutas por direitos sexuais no Brasil. Em Pauta, 34(12), 155-178.

Anzaldúa, G. (1999) Borderlands/La Frontera: The New Mestiza. San Francisco: Aunt Lute.

Agostini, C. A., Hojman, D., Román, A. \& Valenzuela, L. (2016). Segregación residencial de ingresos en el Gran Santiago, 1992-2002: una estimación robusta. EURE (Santiago), 42(127), 159-184. https://doi.org/10.4067/S0250-71612016000300007

Bastos, C. B. (2016). Performance and Feminisms: dialogues to inhabit the crossroadbody. Urdimento - Revista de Estudos em Artes Cenicas, 2(27), 62-77.

Beas, R., Anduaga-Beramendi, A., Maticorena-Quevedo, J., Vizcarra-Melgar, J., \& Mariño, C. (2016). Are dating apps a public health issue? Medwave, 16(08), e6536-e6536. https://doi.org/10.5867/medwave.2016.08.6536

Brah, A. (1996) Cartographies of diaspora: contesting identities. London/New York: Routledge.

Bourdieu, P. (1990). Sociologia y Cultura. México: Editorial Grijalbo.

Brown, G. (2012). Homonormativity: A Metropolitan Concept that Denigrates "Ordinary" Gay Lives. Journal of Homosexuality, 59(7), 1065-1072. doi:10.1080/00918369.20 12.699851

Cortés, C. (2016). Experiencia social e indentidad territorial en barrio Bellas Artes: una mirada desde la gaycidad, región metropolitana, Chile. Anales Sociedad Chilena de Ciencias Geograficas, 47, 47-56.

Costa, J. (2013). Life control, interseccionality and politics of empowerment: female domestic workers' political organizations in Brazil. Estudos Históricos (Rio de Janeiro), 26(52), 471-489.

Crenshaw, K. (1991). Mapping the margins: Intersectionality, identity politics, and violence against women of color. Stanford law review, 1241-1299. 
Creswell, J. W., \& Poth, C. N. (2018). Qualitative inquiry and research design: Choosing among five traditions (40 Edition). Los Angeles: SAGE Publications, Inc.

Deleuze, G., \& Guattari, F. (1985). El anti-Edipo. Capitalismo y esquizofrenia. Barcelona: Paidós Iberica.

Faris, M. J. (2019). Queering Networked Writing: A Sensory Authoethnography of Desire and Sensation on Grindr. En W. Banks, M. Cox, \& C. Dadas (Eds.), RE/ORIENTING WRITING STUDIES Queer Methods, Queer Projects (pp. 127-149). Logan: Utah State University Press.

Foucault, M. (2010). El cuerpo utópico. Las heterotopías. Buenos Aires: Nueva Visión.

Gómez Beltrán, I. (2018). Grindr y la masculinidad (hegemónica): aproximación comparativa del rechazo a los hombres femeninos. Estudios Sociológicos de El Colegio de México, 37(109). https://doi.org/10.24201/es.2019v37n109.1644

Gómez, E. (2018). La identidad de los usuarios de aplicaciones para telefonos moviles destinadas a hombres que tienen sexo con hombres (HSH). El estudio de caso de Grindr. En L. Camarero, E. Hergueta-Covacho, \& C. Villalonga (Eds.), Comunicar y educar en la ubicuidad. Aprendizaje movil, Apps, y MOOCs desde una metodologia inteRmetodologica ubicua (pp. 77-98). Sevilla, España: Ediciones Egregigus.

Hakim, C. (2012). Capital erótico. El poder de fascinar a los demás. Barcelona: Debate.

Hancock, A. M. (2011). Solidarity politics for Millennials: A guide to ending the oppression olympics. New York: Palgrave Macmillan.

Hill Collins, P. (2000) Black feminist thought: knowledge, consciousness, and the politics of empowerment. New York \& London: Routledge.

Lemebel, P. (2009). Loco afán : crónicas de sidario. Barcelona: Seix Barral.

Likke, N (2010) Feminist Studies, A guide to intersectional Theory, Metodology and Writing. New York:Routledge.

Mowlabocus, S. (2010). Gaydar Culture: Gay men, technology and embodiment in the digital age. London: Routledge.

Navajas-Pertegás, N. (2017). La gordofobia es un problema del trabajo social. AZARBE, $0(6), 37-46$.

Raj, S. (2011). Grindring Bodies: Racial and Affective Economies of Online Queer Desire. Critical Race and Whiteness Studies, 7.2, 1-12.

Reyes, S. (2018). Terror y morBBo en visualidades del contagio VIH/sida en Chile (19902018). ESCENA. Revista de Las Artes, 150-166. https://doi.org/10.15517/ es.v0i0.35612

Roth, Y. (2016). Zero Feet Away: The Digital Geography of Gay Social Media. Journal of Homosexuality, 63(3), 437-442. https://doi.org/10.1080/00918369.2016.1124707

Salazar, G. (2011). Políticas queer y capitalismo: Revoluciones moleculares en el Chile postdictatorial. Revista Sociedad y Equidad, (1).

Sedgwick, E. K. (1998). Epistemología del armario. Barcelona: Ediciones de la Tempestad. 
Spargo, T. (2004). Foucault y la teoría queer. Barcelona: Gedisa Editorial.

Suárez García, C. (2017). Gordofobia: Un tránsito entre la enfermedad y la cosificación del cuerpo femenino. Recuperado desde from http://riull.ull.es/xmlui/handle/915/5641

- Sobre los autores:

Luis Parra es sociólogo de la Universidad de Concepción.

Augusto Obando es matrón, Doctor en Procesos Sociales y Politicos en América Latina. Académico del Departamento de Salud Pública de la Facultad de Medicina de la Universidad de la Frontera. Mail: augusto.obandođagmail.com

- ¿Como citar?

Parra, L. \& Obando, A. (2019). De armarios virtuales a campos digitalesde exterminio: interseccionalidad de Grindr fábrica de gaycidad chilena. Comunicación y Medios, (40), 98-113. 